\title{
O Design Institucional da União Europeỉa e sua Repercussão nas Relações com a América Latina*
} Patrícia Luiza Kegel** e Mohamed Amal***

\section{Introdução}

Sob uma perspectiva estritamente jurídico-formal, cabe indagar de que forma a União Europeia (UE) atua como ator político interna-

\footnotetext{
* Artigo recebido em 17 de setembro de 2010 e aprovado para publicação em 3 de dezembro de 2010. Os autores agradecem ao Center for European Integration Studies (ZEI) da Universidade de Bonn, Alemanha, na pessoa de seu diretor prof. dr. Ludger Künhardt, pelo apoio durante o estágio de pesquisa naquele instituto.

** Pós-doutora em Direito pela Universidade Federal de Santa Catarina (UFSC), professora no Programa de Pós-graduação em Desenvolvimento Regional na Universidade de Blumenau, membro fundadora da European Union Studies Association (ECSA), no Brasil, e pesquisadora do Zentrum fur Europäische Integrationsforschung (ZEI), da Universidade de Bonn, Alemanha. E-mail: paluke @ furb.br.

*** Doutor em Engenharia de Produção pela Universidade Federal de Santa Catarina (UFSC) e professor de Economia Internacional e de Negócios Internacionais do Programa de Pós-graduação em Administração da Universidade de Blumenau (FURB). E-mail: amal@ furb.br.
}

CONTEXTO INTERNACIONAL Rio de Janeiro, vol. 34, noำ 1, janeiro/junho 2012, p. 223-254. 
cional, na medida em que ela não se constitui em uma organização internacional tradicional ou sequer Confederação de Estados. No entanto, quando outros atores internacionais se relacionam política e comercialmente com a UE, eles tendem a considerá-la como um todo político e orgânico, da mesma forma que um Estado nacional.

Contudo, a União Europeia não é uma unidade territorial e administrativa, usualmente conhecida por Estado soberano. Partindo do pressuposto que uma das características dos Estados nacionais é a vinculação de suas estratégias internacionais, sob a liderança e a responsabilidade política de um governo eleito, o qual garante a unidade da atuação externa deste Estado, a UE possui, ao contrário, características institucionais próprias, inclusive em relação ao estabelecimento de estratégias políticas e comerciais de médio e longo prazo. Neste sentido, a entrada em vigor do Tratado de Lisboa alterou a configuração jurídico-institucional tradicional em relação à atuação comercial externa europeia e, ao eliminar determinados focos internos de conflito, introduziu novas interrogantes quanto à sua autonomia em relação ao conjunto da atuação internacional da União Europeia.

Nesta perspectiva, o presente artigo tem por objetivo discutir o alcance do novo design institucional da política comercial comum europeia, no âmbito de suas relações com a América Latina e o Caribe e em suas negociações com o Mercosul. O pressuposto teórico adotado baseia-se no neoinstitucionalismo, segundo o qual o processo decisório europeu é determinado por seu quadro institucional sui generis, no qual interagem, em diferentes configurações, instâncias supranacionais e intergovernamentais.

Para tanto, além desta introdução, serão inicialmente apresentadas as principais alterações da política comercial comum efetuadas pelo Tratado de Lisboa e, em um segundo momento, as relações da União Europeia com o espaço da América Latina e do Caribe, em particular com o Mercosul. As considerações finais procuram estabelecer a in- 
ter-relação entre a nova política comercial comum europeia - marcada pelo aumento expressivo das competências do Parlamento Europeu e por sua vinculação ao conjunto da Ação Externa da União - e as políticas para a América Latina, o Caribe e o Mercosul.

\section{Instituições e Integração Europeia}

Por "instituições", compreende-se um conjunto normativo orientado a determinados objetivos, e os instrumentos que garantam sua execução, com o intuito de dirigir o comportamento individual em determinada direção. Desta forma, as instituições são as restrições criadas pela sociedade e que constituem a forma através da qual ocorrem as interações econômicas, sociais e políticas de seus membros. As restrições definem os limites dentro dos quais ocorrem as trocas e as escolhas individuais, fixando direitos, proibições e sanções previstas em lei e convenções sociais.

Ao reduzir a incerteza, as instituições estimulam a cooperação e melhoram a coordenação econômica, pois proporcionam uma estrutura à vida cotidiana, definindo e limitando o conjunto de escolhas dos indivíduos. Desta forma, a eficiência dos mercados depende das instituições de suporte capazes de definir e fornecer regras de jogo para o seu funcionamento. Como as instituições regulam e limitam a atividade humana, ao proibir, obrigar ou permitir determinado comportamento, os indivíduos podem formar expectativas confiáveis sobre o comportamento de outros atores e necessitam investir poucos recursos para a concretização e a consolidação de suas transações econômicas (NORTH, 1993).

No âmbito internacional, e mesmo que com características distintas, as Instituições Internacionais são criadas com o objetivo de gerar um ambiente de maior previsibilidade e segurança nas relações internacionais e, desta maneira, contornar problemas de cooperação entre 
Estados. Desta forma, as instituições operam como lócus de afirmação de vontades e reivindicações, implicando na composição de interesses distintos. Quanto mais institucionalizadas forem as relações internacionais, maior a confiança sobre as informações e expectativas mútuas, maior a segurança e, principalmente, mais relativizadas são as relações de força e poder efetivo entre seus membros. Por outro lado, sua permanência, robustez e evolução serão determinadas pelo cálculo dos ganhos obtidos pela cooperação entre Estados e pela capacidade de adequação destes mesmos Estados ao seu quadro institucional interno.

No quadro desta perspectiva institucional de análise, os acordos de integração regional de maior alcance dão origem a organizações internacionais destinadas a implementar a cooperação econômica, comercial e, eventualmente, política, consideradas como objetivo principal do acordo. Em seu âmbito, são criadas estruturas institucionais destinadas a administrar o processo propriamente dito. Dependendo da profundidade da integração desejada, o ambiente institucional criado para gerenciar a implantação e o desenvolvimento dos objetivos acordados, poderá ser mais ou menos intenso. As decisões adotadas nas instâncias criadas para administrar o bloco, passam a substituir as instâncias nacionais correspondentes, nas áreas em que o Tratado Constitutivo reservou para as competências do bloco. Ou seja, as informações e expectativas dos agentes econômicos deixam de derivar dos governos nacionais e passam a estar vinculadas às instâncias conjuntas.

Em relação ao processo de integração europeu, a concepção intergovernamental, de cunho neofuncionalista, afirma que as instituições comunitárias foram criadas pelos Estados nacionais para que houvesse maior eficiência no alcance de seus objetivos. Para Grimmel e Jakobeit (2009), no entanto, o desenvolvimento histórico da integração europeia demonstra que os Estados (atores primários da integração) gradativamente passam a perder o controle sobre as instituições. 
Este fenômeno pode ser explicado através de um conjunto de mecanismos intergovernamentais e supranacionais, através dos quais as instituições deixam de ser pura criação dos Estados, passando a desenvolver dinâmicas próprias, com competência executiva abrangente, sistema jurisdicional próprio e autônomo e a capacidade de propor e alterar políticas. Mesmo que as instituições supranacionais exerçam suas competências no limite do tolerado através do mecanismo do spill-over, em que direitos de soberania são transferidos pelos Estados em favor das instituições supranacionais, os Estados conseguem retardar o desenvolvimento, ao menos parcial, de consequências indesejadas. ${ }^{1}$ E isso ocorre porque existe uma densa teia de entrelaçamentos em todos os níveis e esferas, que tem por consequência prática a formação de limites, aos quais o conjunto dos atores envolvidos está submetido.

Nessa perspectiva, adotamos o pressuposto teórico do neoinstitucionalismo, para o qual o design institucional comunitário determina o conjunto do processo decisório e seus resultados, e define o modo de participação e competências, tanto dos órgãos intergovernamentais e supranacionais quanto das entidades da sociedade civil (BIELING; LERCH, 2006). Em consequência, a atuação externa da União Europeia pode ser em grande medida explicada pela configuração institucional comunitária e pelos consequentes mecanismos de interação e fixação de limites dos atores supranacionais e nacionais.

O objetivo deste artigo é estudar a formatação jurídica da dimensão internacional da União Europeia, com a entrada em vigor do Tratado de Lisboa. Em especial, será analisado o novo arcabouço institucional da política comercial comum (PCC), ou seja, o quadro institucional específico no qual se desenvolvem as relações comerciais externas da União Europeia, e de seus possíveis reflexos no conjunto das relações União Europeia-América Latina e Caribe, e no processo negociador com o Mercosul. 


\section{Os Antecedentes da Política} Comercial Comum da $\mathrm{UE}^{2}$

Desde sua criação com o Tratado de Maastricht, a concepção da União Europeia refletiu a necessidade de um marco institucional que articulasse as Comunidades Europeias, ou seja, o pilar comunitário, com os demais pilares intergovernamentais, especificamente a política externa e de segurança comum e a cooperação policial e judicial em matéria penal, desenvolvidas dentro dos padrões usuais de cooperação entre Estados. Neste sentido, o de ser um marco institucional, a UE não possuía personalidade jurídica própria, tanto interna quanto externamente, e, portanto, sem capacidade de celebrar qualquer tipo de acordo internacional. A personalidade de direito internacional público estava restrita à Comunidade Europeia (CE), a qual, por sua vez, também não constituía uma unidade territorial-política-administrativa, normalmente conhecida por Estado soberano. Ao contrário, a CE era uma organização internacional, de características supranacionais, à qual pertenciam, no momento da celebração do Tratado de Lisboa, 27 Estados-membros.

Ocorre, contudo, que por características peculiares ao Tratado da Comunidade Europeia (TCE), ${ }^{3}$ não foi realizado um catálogo estrito e coerente de repartição de competências entre os Estados-membros e a Comunidade, ocasionando uma tensão que opôs, historicamente, Comunidade e Estados-membros. Esta tensão também foi refletida nas disputas entre a Comissão (representante legítima dos interesses comunitários) e o Conselho (compreendido como porta-voz dos interesses nacionais), tornando o sistema decisório interno da Comunidade bastante complexo, ao envolver 28 perspectivas eventualmente distintas: a da Comunidade, juntamente com suas várias instituições nem sempre atuando de forma harmoniosa, e a de cada um dos Estados-membros. 
Na ausência de um quadro definido de repartição de competências, os acordos comerciais celebrados pela CE subdividiam-se em duas fórmulas de atuação distintas: os acordos exclusivos e os acordos mistos. Os acordos exclusivos eram celebrados exclusivamente pela Comunidade e neste caso apenas ela atuava internacionalmente porque possuía competência para tanto. Nos acordos mistos, a competência comunitária em determinada matéria não era suficiente, necessitando da coparticipação internacional dos Estados-membros dentro do quadro geral de repartição de competências e, principalmente, tal como interpretado pelo Tribunal de Justiça das Comunidades Europeias (TJCE). ${ }^{4}$

Nos acordos celebrados exclusivamente pela $\mathrm{CE}$, em razão da natureza bicéfala do executivo comunitário, cabia à Comissão entrar em contato com Estados terceiros e apresentar ao Conselho suas conclusões a respeito. A autorização para a abertura das negociações era de competência privativa do Conselho, deliberando por maioria qualificada. Na hipótese favorável, a Comissão, respeitando as diretrizes do Conselho, passava à fase das negociações, assessorada por comitês especiais integrados por representantes governamentais (Comitê, art. 133). ${ }^{5}$

Nos acordos estritamente comerciais, o Parlamento Europeu possuía uma competência apenas consultiva não vinculante. Já nos acordos de associação e cooperação, nos acordos com consequências orçamentais significativas, nos acordos que implicassem a alteração de um ato adotado através da codecisão e nos acordos que criassem um quadro institucional, o Parlamento Europeu contava com um verdadeiro poder de veto, pois na hipótese de seu parecer ser desfavorável, o Conselho estava impedido de concluir o acordo. Se as negociações chegassem a um termo positivo para todas as partes, e o parecer do Parlamento Europeu fosse favorável quando necessário, cabia então ao Conselho, exclusivamente, manifestar o consentimento em nome da Comunidade Europeia ao acordo internacional a ser celebrado. Já 
os acordos mistos eram bem mais amplos e abrangentes que os exclusivos, pois incluíam áreas onde a competência era compartida entre a Comunidade e seus Estados. Contudo, apresentavam a enorme desvantagem de necessitarem de 28 procedimentos distintos de ratificação (um comunitário e 27 nacionais) e, consequentemente, qualquer governo ou Parlamento nacional podia bloquear a celebração do conjunto do acordo. ${ }^{6}$

De modo geral, o estabelecimento de uma União Aduaneira e posteriormente de um mercado comum resultou na necessidade de uma manifestação comercial conjunta da Comunidade e de seus Estados-membros perante países terceiros. Nesse sentido, a efetivação do mercado interno e as vantagens dele provenientes, implicaram na adoção de medidas uniformes destinadas a garanti-lo, ou seja, uma política comercial comum como complemento das políticas internas orientadas a implementar o processo de integração regional.

Desta forma, a condução da política comercial comum foi caracterizada por dois traços distintivos. De um lado, a expansão gradativa das competências comunitárias sobre as nacionais, que ocorreu, em grande medida, pelo forte desenvolvimento na Comissão de um quadro técnico especializado em questões comerciais, levando os Estados a ceder cada vez mais atribuições. Em segundo lugar, a modulação da política comercial comunitária através da estrita cooperação entre a Comissão e os representantes dos Estados (Comitê, art. 133) tornou-a bastante tecnocrática, no sentido de haver um predomínio (mesmo que eventualmente relativizado) de elementos técnicos sobre os políticos. No entanto, a crescente complexidade das relações econômicas e comerciais internacionais expôs o potencial conflito de seu exercício por parte da Comunidade e de seus Estados-membros, levando à percepção da necessidade de reformar o quadro comunitário de competências e atribuições relacionado à política comercial comum. 


\section{O Design Institucional da União Europeia e}

sua Repercussão nas Relações...

\section{O Tratado de Lisboa, a Ação Externa da União e sua Política Comercial Comum}

Em 2007, com o intuito de superar a situação de paralisia ocasionada pela não ratificação do "Tratado que estabelece uma Constituição para a Europa", 7 foi convocada uma Conferência Intergovernamental (CIG 2007), com o objetivo de alterar os tratados em vigor (e não mais substituí-los, como no caso da Constituição). Seus resultados foram aprovados e em dezembro de 2007, em Lisboa, foi celebrado o novo tratado que altera os tratados preexistentes. A configuração jurídica utilizada foi a de um tratado reformador, nos mesmos moldes dos Tratados de Amsterdã e Nice. Consequentemente, a União Europeia mantém como base jurídica dois tratados distintos: o Tratado da União Europeia (TUE) e o Tratado para Funcionamento da União Europeia (TFUE), o qual substitui o antigo Tratado da Comunidade Europeia.

O Tratado de Lisboa produziu uma notável simplificação das estruturas da União Europeia, ao abolir sua divisão em pilares supranacional e intergovernamentais, estabelecendo uma única União, que substitui e sucede a atual Comunidade Europeia. Desta forma, o TUE pode ser considerado um tratado básico, pois regulamenta os aspectos mais relevantes da União Europeia, enquanto que o TFUE, ao normatizar os aspectos institucionais, procedimentais, e de competência, entre outros, pode ser considerado um tratado de operacionalização. Nesta lógica, a União substitui e sucede à Comunidade Europeia, sendo dotada de uma personalidade jurídica única, fundada em ambos os tratados, os quais possuem o mesmo valor jurídico. Assim, o termo "Comunidade" foi substituído em todo o texto por "União" e o termo "Comunitário" por "da União". 
Sob a perspectiva de suas relações externas, a outorga explícita da personalidade jurídica internacional à União Europeia, ${ }^{8}$ constituiu um notável avanço em um duplo aspecto. De um lado, encerra o debate sobre a existência ou não de uma personalidade jurídica implícita da União Europeia e lhe permite ingressar em outras organizações internacionais, celebrar acordos internacionais, demandar e ser demandada perante instâncias internacionais, e transformar as Delegações da Comissão no exterior em Delegações da União. Por outro lado, opera a extinção da Comunidade Europeia como sujeito de direito internacional público, suprimindo, assim, a dualidade de competências, de atuação e de representação no exterior. Esta dupla inovação que outorga personalidade jurídica internacional à União Europeia e, simultaneamente, extingue a Comunidade Europeia, foi a principal contribuição do Tratado de Lisboa para conferir maior visibilidade, coerência e eficiência à ação externa da UE.

Historicamente, uma das maiores deficiências relacionadas à ação externa da UE estava centrada no déficit de articulação entre o pilar comunitário (supranacional) e o intergovernamental, expresso na multiplicação de responsabilidades e ausência de efetividade por conta da unanimidade necessária à adoção de decisões no âmbito da política externa e de segurança comum. Nesta esfera, portanto, um dos objetivos confessos do Tratado de Lisboa (e da CIG 2007) foi evitar contradições e conflitos internos, além de otimizar recursos e resultados. Nesta perspectiva, as disposições que normatizam as relações externas da União foram concentradas na Parte V do TFUE, na qual se encontram as disposições gerais relativas ao tema, as competências expressas relacionadas ao estabelecimento de uma união aduaneira, à política comercial comum, à política de cooperação e ajuda humanitária, às medidas restritivas, à celebração de acordos internacionais, e à cláusula de solidariedade. Também são incluídos dispositivos que ampliam a capacidade da União de celebrar acordos internacionais com outros sujeitos de direito internacional, porém 
não se menciona a responsabilidade internacional da União e nem sua participação explícita em mecanismos de solução de controvérsias.

De forma mais ampla, desde a Declaração de Laeken que originou as discussões em torno da Constituição Europeia, um dos itens mais debatidos no contexto das articulações entre as instâncias supranacionais e os Estados-membros, foi o da repartição de competências. No Tratado de Lisboa, optou-se por dispersar o tratamento jurídico a respeito, com dispositivos sobre os princípios que regem as competências no TUE, e a descrição dos tipos e sua natureza no TFUE. Foi colocada uma ênfase especial no princípio segundo o qual as competências não atribuídas à União pertencem aos Estados-membros. Também foram mantidas as disposições tradicionais sobre o princípio da atribuição de competências, subsidiariedade e proporcionalidade, e, na ausência de um catálogo expresso das competências reservadas aos Estados, foi introduzido o art. $4^{\circ}$ do TUE, que estabelece a obrigação da União em respeitar a identidade nacional de seus Estados-membros. $^{9}$

O Tratado de Lisboa adota a evolução doutrinária e jurisprudencial a respeito, e apresenta uma tipologia da qual emergem três categorias básicas: as competências exclusivas da União e nas quais apenas ela atua, ${ }^{10}$ as competências que a União possui com o objetivo de realizar ações que apoiem, complementem ou coordenem a ação dos Estados-membros, ${ }^{11} \mathrm{e}$, em todas as demais áreas, as competências que a União compartilha com seus Estados-membros. ${ }^{12}$ Em cada uma destas categorias, o Tratado de Lisboa incluiu a lista de temas e sua definição conceitual.

No âmbito de suas relações econômicas externas, a partir do estabelecimento da União Aduaneira, consolidou-se a competência exclusiva da UE em desenvolver e implementar a política comercial comum em relação a Estados terceiros e organizações internacionais, 
em dois níveis distintos. De um lado, a UE participa ativamente da Organização Mundial do Comércio (OMC) como membro pleno, contribuindo para a formulação de regras para o sistema comercial multilateral. De outro, a União se relaciona bilateralmente com outros países ou regiões através de acordos comerciais. No entanto, como já mencionado anteriormente, a PCC abrangia apenas o comércio de bens, permanecendo o comércio de serviços e determinados aspectos da Propriedade Intelectual no regime de competências compartidas com os Estados-membros. Além de todos os problemas relacionados à divisão de competências e à acomodação de interesses nacionais, este sistema não dava conta do fato de que o processo de globalização alterou os denominadores do comércio internacional, tornando o comércio de serviços e de propriedade intelectual tão ou mais importante do que o de mercadorias (ESTEVE, 2009).

Reconhecendo a necessidade de uma manifestação comercial conjunta em todas as áreas, o art. 207 do TFUE ampliou substancialmente seu conteúdo, com a inclusão do comércio de serviços, propriedade intelectual e investimentos diretos externos. Com a nova configuração do Tratado de Lisboa, a União passa a exercer com exclusividade sua competência externa perante a OMC e demais parceiros comerciais. No entanto, e mesmo assim, a par da ampliação do conteúdo da PCC, manteve-se a denominada "exceção cultural”, pela qual os acordos comerciais relativos a serviços culturais e audiovisuais permanecem submetidos à votação por unanimidade no Conselho, com o objetivo de proteger e permitir que a cultura própria de cada Estado-membro possa se desenvolver. Outra classe de acordos que também exige unanimidade são os relativos ao comércio de serviços sociais, educativos e de saúde, sempre que tais acordos possam perturbar gravemente a organização destes serviços a nível nacional e afetar sua prestação por parte dos Estados-membros.

É interessante observar que o art. 216 do TFUE ${ }^{13}$ agrega uma cláusula horizontal de competência, ao permitir à União a exclusividade de 
celebração de acordos, mesmo quando não expressamente previsto. De certa maneira, significa a positivação da denominada "Doutrina AETR", a partir da qual o Tribunal de Justiça Europeu desenvolveu o chamado "paralelismo das competências internas e externas", e que permitiu à então Comunidade Europeia utilizar sua competência exclusiva para celebrar acordos internacionais, mesmo que não tivessem sido expressamente previstos.

Outra modificação substancial na PCC é a utilização do processo legislativo ordinário (PLO) como procedimento para aprovar as medidas de aplicação desta política. O PLO é o novo termo utilizado para designar o procedimento de codecisão, que tradicionalmente associa o Parlamento Europeu (PE) ao procedimento decisório da União. Neste caso, o PE é igualmente competente para se manifestar sobre os acordos comerciais que a União concluir com Estados terceiros.

Como já mencionado anteriormente, sob a vigência das disposições relativas à PCC no Tratado da Comunidade Europeia, o Parlamento Europeu não estava incluído no procedimento de negociação e celebração de acordos comerciais. Após a entrada em vigor do Tratado de Lisboa, a influência do PE no âmbito da PCC aumentou substancialmente. A condução das negociações permanece com a Comissão; contudo, os contornos da política comercial comum passam a ser decididos em conjunto pelo Conselho e pelo PE; a Comissão tem o dever de informar o Parlamento sobre conteúdo e estágio do desenrolar das negociações; e, por fïm, tornou-se necessária a consulta prévia do PE para a celebração de acordos comerciais. ${ }^{14}$ Por sua vez, o aumento das competências do Parlamento Europeu no âmbito da política comercial comum traduziu-se em uma aspiração à maior influência nas negociações comerciais internacionais, tanto bilaterais quanto aquelas relacionadas à Organização Mundial do Comércio. Para tanto, o PE possui em sua estrutura um órgão de assessoramento para questões relacionadas à PCC. Trata-se da Comissão de Comércio Internacional, com competência, entre outros, sobre assuntos relati- 
vos à definição e à execução da PCC, das relações com a OMC e sobre o conjunto de suas relações econômicas externas.

Da mesma forma, é importante detalhar, mesmo que brevemente, os temas não comerciais incluídos no Título $\mathrm{V}$ do TFUE. Em relação à cooperação com países terceiros e à política de desenvolvimento, a principal alteração introduzida pelo Tratado de Lisboa é a criação de uma base jurídica específica para a ajuda humanitária, mantendo, em grandes linhas, as disposições sobre cooperação já existentes a respeito. Por sua vez, o art. 215 do TFUE regula as medidas restritivas ou sanções que o Conselho pode adotar em relação a Estados terceiros, pessoas físicas ou jurídicas, grupos ou entidades não estatais no âmbito da política externa e de segurança comum. Tais sanções consistem na redução ou na interrupção das relações econômicas ou financeiras da União com o sujeito das medidas, por maioria qualificada, por proposta do alto representante.

Na atual configuração do Tratado de Lisboa, o art. 205 do TFUE dispõe que a ação da União na cena internacional é baseada em determinados objetivos e deve ser conduzida em conformidade com as disposições gerais enunciadas no Capítulo 1, do Título V do TUE. Esses incluem objetivos gerais, em particular a defesa de "democracia, Estado de direito, universalidade dos direitos humanos e das liberdades fundamentais, princípios da igualdade e solidariedade e respeito pelos princípios da Carta das Nações Unidas e do direito internacional". Mas também estão inseridos alguns objetivos bastante concretos, tais como o apoio ao desenvolvimento sustentável nos planos econômico, social e ambiental, a erradicação da pobreza, a melhora da qualidade do ambiente, a gestão sustentável dos recursos naturais, a cooperação multilateral, a boa governança global, e, last but not least, a integração de todos os países na economia mundial, inclusive através da eliminação progressiva dos obstáculos ao comércio internacional. 
Tradicionalmente, a União Europeia tem-se utilizado da PCC como instrumento habitual para viabilizar determinados objetivos estratégicos ou alcançar os propósitos mais amplos de sua política externa. Esta instrumentalização, contudo, sempre teve contornos mais indiretos, como, por exemplo, a negociação de acordos de associação com países vizinhos à União, como forma de induzir à estabilidade econômica e, principalmente, política. ${ }^{15}$ Com este objetivo, a UE sempre negociou com sua principal vantagem de política externa o acesso a um mercado integrado por 27 Estados. Neste sentido, a inserção da política comercial comum no âmbito das demais competências externas da UE e sua vinculação aos princípios e objetivos da ação externa da União levantam a questão da tendência, ou tentação, por parte da União, em utilizar a política comercial na perseguição de seus outros objetivos externos (WOOLCOCK, 2008, p. 22).

\section{As relações entre a União Europeia e a América Latina e o Caribe e a situação específica do Mercosul}

O histórico da aproximação política europeia e latino-americana, impulsionada nos anos 1980, culminou com a realização, em 1999, da I Reunião de Cúpula dos Chefes de Estado e Governo dos Países-membros da América Latina, do Caribe e da União Europeia, no Rio de Janeiro. É pertinente observar que, desde o início, as três colunas que fundamentavam o entendimento sobre parceria estratégica entre ambas as regiões, notadamente a cooperação econômica, o diálogo político e a ajuda ao desenvolvimento, referiam-se, quase que exclusivamente, a temas não econômicos.

A II Cúpula, de 2002, em Madri, obteve certo êxito ao anunciar a conclusão das negociações com o Chile (de certa forma, à revelia das reuniões de cúpula) e o avanço do diálogo político e de cooperação. 
Já os temas propostos para a III Cúpula, de 2004, em Guadalajara, a saber, a consolidação de uma associação estratégica birregional, bem como integração e coesão social, também não tratam de pontos específicos, através dos quais propostas concretas pudessem ser negociadas. Na IV Cúpula, de 2006, em Viena, foi acertada a abertura das negociações entre a UE e a América Central e a Comunidade Andina de Nações (CAN) para a formação de um acordo de associação. $\mathrm{Na} \mathrm{V}$ Cúpula, de 2008, em Lima, foi decidida a criação de uma Assembleia Parlamentar Euro-Latino-Americana e o diálogo sobre migração. A VI Cúpula, ocorrida em Madri, em maio de 2010, teve como principais objetivos considerar o impacto da crise sobre emprego e política social, definir a criação da Fundação União Europeia-América Latina e Caribe, com o intuito de envolver a sociedade civil no diálogo político, e assinalar a cooperação em questões de interesse comum entre a América Latina e o Caribe. Além desses, o objetivo de maior interesse, a retomada das negociações entre UE e Mercosul, não produziu os efeitos esperados, na medida em que ambas as partes mantiveram suas posições, sem ofertas significativas nas áreas agrícola (UE) e industrial (Mercosul).

O Quadro 1 apresenta, abaixo, dados relativos ao comércio da União Europeia com América Latina, Ásia e África. Mesmo não considerando as relações comerciais da UE com países extrabloco, e considerando apenas os países em desenvolvimento, os dados não apontam para uma mudança significativa no papel da América Latina na estratégia comercial europeia.

Desta maneira, como pode ser observado no Quadro 1 acima, as relações comerciais com a América Latina mantiverem-se relativamente estáveis num patamar abaixo de $10 \%$ de participação nos fluxos comerciais com países extrabloco europeu. Vale ressaltar que a participação da América Latina nos fluxos de comércio com o bloco é abaixo da participação da África, que, durante o mesmo período, teve uma ampliação de sua participação nos fluxos comerciais. Por outro 
O Design Institucional da União Europeia e sua Repercussão nas Relações...

\section{Quadro 1}

Relações Comerciais da UE com América Latina e Países da Ásia, Dados em \%

\begin{tabular}{|l|r|r|r|r|r|r|}
\hline & $\mathbf{1 9 9 9}$ & $\mathbf{2 0 0 4}$ & $\mathbf{2 0 0 5}$ & $\mathbf{2 0 0 6}$ & $\mathbf{2 0 0 7}$ & $\mathbf{2 0 0 8}$ \\
\hline Exportações para a América Latina & 6,8 & 5,0 & 5,2 & 5,5 & 5,8 & 6,1 \\
\hline Exportações para a Ásia & 21,1 & 22,3 & 21,6 & 21,8 & 22,0 & 21,5 \\
\hline Exportações para a África & 8,5 & 8,1 & 8,3 & 8,0 & 8,4 & 9,2 \\
\hline Importações da América Latina & 5,2 & 5,6 & 5,6 & 5,9 & 6,2 & 6,2 \\
\hline Importações da África & 7,8 & 8,5 & 9,4 & 9,3 & 9,0 & 10,1 \\
\hline Importações da Ásia & 34,9 & 36,3 & 35,2 & 35,6 & 36,5 & 34,5 \\
\hline
\end{tabular}

Fonte: Elaboração própria, com base nos dados da Eurostat (2009).

lado, os países da Ásia, embora tendo uma participação relativamente estável tanto em termos de exportação, como de importação, apontam para uma posição estratégica que se manteve robusta e sustentável apesar das mudanças dos cenários econômicos internacionais.

Com relação aos fluxos comerciais entre a União Europeia e a América Latina e o Caribe, os dados mostram que os fluxos nominais entre as duas regiões dobraram desde a década de 1990. Em 2006, o volume de comércio entre as duas regiões foi de 160 bilhões de euros, atrás apenas dos Estados Unidos, e a UE consolidou-se como principal origem dos Investimentos Diretos Externos na região, transformando, sob a perspectiva latino-americana, o bloco econômico europeu num parceiro estratégico. ${ }^{16}$

Em especial, a importação europeia das commodities agrícolas provenientes dos Estados do Mercosul aumentou substancialmente nos últimos anos, facilitada pela concessão de vantagens no âmbito do Sistema Geral de Preferências. Da mesma forma, a UE também inclui a maioria dos Países pertencentes ao Sistema de Integração Centro-Americano ${ }^{17}$ e os Países da Comunidade Andina ${ }^{18}$ em seu Sistema Global de Preferências. Já com México e Chile, a União Europeia mantém relações comerciais mais intensas. Com o México, desde 2000 a UE possui um acordo de livre comércio. E com o Chile, desde 
2005, um acordo de associação que prevê, além da abolição das barreiras ao comércio, um trabalho conjunto em questões políticas e nas áreas de cultura, educação e ciência. Em relação a esses acordos de maior densidade comercial e econômica, é importante observar que a liberalização comercial pretendida entre a União Europeia e o Chile e entre a UE e o México não apresentaram aspectos conflitivos mais graves, já que ambos os países não são grandes exportadores agrícolas e os Estados Unidos são o principal destino de suas exportações.

No entanto, com exceção dos acordos com Chile e México, as negociações e a celebração de acordos com o restante dos países da América Latina e do Caribe desenvolveram-se dentro de um quadro de reduzido comprometimento jurídico e objetivos concretos (GRATIUS, 2006). São considerados, portanto, acordos "vazios", na medida em que são redigidos em termos muito amplos, com alto grau de vagueza na terminologia utilizada, e sem compromissos jurídicos específicos, que possam gerar, de forma autônoma, um conjunto de direitos e deveres às partes contratantes (KEGEL, 2007).

Neste contexto, a Comissão manteve suas metas em relação à América Latina, conservando, como fundamentais, os seguintes pontos no relacionamento birregional: ${ }^{19}$ combate à pobreza e às desigualdades sociais, melhoria do nível de ensino e, em especial, a promoção da integração regional através da negociação de acordos de associação com as sub-regiões da América Latina, notadamente Mercosul e Comunidade Andina. Tal estratégia, contudo, não tem sido bem-sucedida, na medida em que têm ocorrido sucessivas postergações e atrasos. No caso das negociações para um acordo de associação iniciadas em 2007 com a Comunidade Andina, as críticas ao livre comércio, base de um futuro acordo de associação, efetuadas pelo Presidente da Bolívia, Evo Morales, ${ }^{20}$ tiveram por efeito prático a paralisação das negociações entre ambas as regiões a partir de 2009. Contudo, a União vem negociando acordos comerciais com alguns países andinos de forma isolada. 
No caso do Mercosul, desde o início dos anos 1990 foram encetadas negociações com a União Europeia, com o objetivo de estabelecer uma relação estratégica birregional e um acordo comercial, inédito, entre duas Uniões Aduaneiras. Mesmo com os capítulos relativos ao "diálogo político" e à "cooperação técnico-científica" já concluídos, tais negociações ficaram estagnadas por uma série de motivos, em particular divergências relacionadas a acesso a mercados e, em especial, o continuamente problemático setor agrícola.

Neste caso específico, ainda em 2004, houve algum esforço de ambas as partes, com o Mercosul, e em especial o governo brasileiro, procurando atender, mesmo que timidamente, algumas solicitações europeias de acesso a mercados em áreas consideradas sensíveis. Da mesma forma, aceitou remeter para as negociações multilaterais no âmbito da OMC questões relacionadas a subsídios e cotas de acesso a mercados agrícolas. Apesar da oferta, modesta, da União Europeia para produtos agrícolas e agroindustriais, as negociações chegaram a um impasse em sua fase final, permanecendo estagnadas desde então.

Sob a perspectiva interna do Mercosul, a estratégia inicialmente desenhada a partir da década de 1990, de formação de sucessivos acordos de liberalização comercial sub-regionais, os quais permitiriam consolidar uma Área de Livre Comércio na América do Sul, não foi bem-sucedida por vários motivos. Inicialmente, não levou em consideração que os interesses concretos e específicos dos membros do Mercosul e de seus vizinhos poderiam ser divergentes, gerando uma dinâmica diversa da idealizada para a integração sul-americana. Esta diversidade de interesses ficou mais patente na medida em que o ambiente econômico dos sócios do Mercosul se deteriorava, chegando, por fim, à convulsão macroeconômica e social argentina em 2001/2002. Porém o fato determinante da interrupção das negociações entre ambos os blocos foi o de que tanto o Mercosul como bloco quanto cada um de seus países e, também, a União Europeia privile- 
giaram as negociações multilaterais na OMC como forma de aceder mercados e, em particular, estabelecer mecanismos que reduzissem o grau de arbitrariedade na imposição de medidas antidumping, a eliminação de subsídios às exportações e a redução de subsídios domésticos para o setor agrícola (RIOS; IGLESIAS, 2008).

Esta situação de estagnação nas negociações de ambos os lados foi significativamente abalada com o desencadeamento da crise financeira e econômica em fins de 2008, que provocou uma séria retração econômica na União Europeia, e que pode ser ilustrada no quadro abaixo sobre o desempenho econômico das principais economias mundiais.

\section{Quadro 2}

Taxa de Crescimento Econômico dos Principais Países Desenvolvidos, em $\%$

\begin{tabular}{|r|r|r|r|r|}
\hline & Zona Euro & Reino Unido & EUA & Japão \\
\hline 2001 & 1,89 & 2,46 & 1,08 & 0,18 \\
\hline 2002 & 0,94 & 2,1 & 1,81 & 0,26 \\
\hline 2003 & 0,82 & 2,81 & 2,49 & 1,41 \\
\hline 2004 & 1,95 & 2,95 & 3,57 & 2,74 \\
\hline 2005 & 1,79 & 2,17 & 3,05 & 1,93 \\
\hline 2006 & 3,1 & 2,85 & 2,67 & 2,04 \\
\hline 2007 & 2,76 & 2,56 & 2,14 & 2,36 \\
\hline 2008 & 0,55 & 0,55 & 0,44 & $-1,19$ \\
\hline 2009 & $-4,04$ & $-4,96$ & $-2,42$ & $-5,03$ \\
\hline
\end{tabular}

Fonte: Fundo Monetário Internacional. Disponível em: <http://www.imf.org>. Acesso em: 7 abr. 2010.

Ao mesmo tempo, o subcontinente americano vem superando relativamente bem este período. Segundo Gratius (2010), a crise financeira internacional deslocou o eixo das relações de poder em direção a um rumo favorável aos Países da América Latina. Apesar de ter havido uma redução de 1,8 \% do PIB em 2009, a região não foi particularmente afetada, não tendo havido crise bancária ou necessidade de au- 
xílio estatal para entidades financeiras em risco de insolvência. Neste sentido, a América Latina não foi a responsável pela crise e nem a sua principal vítima.

Um dos motivos estaria relacionado ao aumento das relações comerciais com a China. Em especial as exportações argentinas e brasileiras do complexo soja, as chilenas de cobre e as peruanas de zinco foram enormemente beneficiadas pela manutenção da demanda chinesa destes produtos, mantendo a economia em crescimento e neutralizando os efeitos da crise. A ampliação da influência chinesa consolida uma tendência já manifesta nos últimos anos, em que o comércio com a Ásia começa a reduzir a importância dos parceiros tradicionais da América Latina, notadamente os Estados Unidos e a União Europeia. Para Gratius (2010), a UE reduziu sua participação no comércio da região de $25 \%$ na década de 1990 para $14,5 \%$ ao final de 2008 e representa hoje o mesmo que a Ásia. Da mesma forma, os Estados Unidos reduziram sua participação como principal destino das exportações latino-americanas, de quase $60 \%$ em 2000 para pouco menos de $40 \%$ em 2008.

O Quadro 3, abaixo, lista apenas as exportações brasileiras, porém exemplifica a tendência regional de fluxo comercial.

Observe-se que apenas com a China existe uma variação positiva e que, isoladamente, ela representa o maior destino das exportações brasileiras, seguida dos Estados Unidos e da Argentina. Apenas quando considerados em conjunto, os países europeus superam a China em participação, absorvendo $15,6 \%$ das vendas externas brasileiras.

Este declínio dos parceiros tradicionais foi acompanhado pelo crescimento substantivo da China, cuja participação no fluxo extrarregional passou de $1 \%$ em 2000 para mais de $8 \%$ em 2008. Por outro lado, e este é um dado bastante preocupante dependendo da perspectiva, o crescimento chinês estaria diretamente associado à adoção de 


\section{Quadro 3}

Principais Países de Destino das Exportações Brasileiras - em US\$ Bilhões (Janeiro a Outubro de 2009)

\begin{tabular}{|c|c|c|c|}
\hline País & Valor & $\begin{array}{c}\text { Variação } \\
2009 / 2008\end{array}$ & Participação \\
\hline 10 China & 14,3 & $20,5 \%$ & $14,6 \%$ \\
\hline 2o Estados Unidos & 10,0 & $-45,5 \%$ & $10,1 \%$ \\
\hline 3으 Argentina & 7,1 & $-40,9 \%$ & $7,2 \%$ \\
\hline 4o Países Baixos & 5,2 & $-27 \%$ & $5,3 \%$ \\
\hline 5o Alemanha & 3,7 & $-32,7 \%$ & $3,8 \%$ \\
\hline 6o Japão & 2,6 & $-30,2 \%$ & $2,7 \%$ \\
\hline 7으 Reino Unido & 2,4 & $-2,4 \%$ & $2,3 \%$ \\
\hline 8o Venezuela & 2,1 & $-28,4 \%$ & $2,2 \%$ \\
\hline 9o Bélgica & 2,0 & $-26,3 \%$ & $2,2 \%$ \\
\hline 10 o Itália & 1,9 & $-38,9 \%$ & $2,0 \%$ \\
\hline
\end{tabular}

Fonte: Dados do Ministério de Desenvolvimento, Indústria e Comércio Exterior do Brasil. Disponível em: <http://www.mdic.gov.br>. Acesso em: 7 abr. 2010.

novas medidas protecionistas por parte de Estados Unidos e União Europeia, o que reduziu as exportações latino-americanas em direção a estes dois mercados, desviando-as para a China (CARDOSO; HOLLAND, 2010).

A percepção, ao menos em parte da América Latina, dos riscos associados a uma dependência excessiva do mercado de commodities asiático convergiu para outra ordem de preocupações europeias. A da nova importância da região como parceira comercial tradicional e potencial destinatária de fluxos de investimento direto.

Desta forma, na esteira desta mesma crise econômica, houve uma retomada das negociações birregionais já no final de 2009, com o objetivo de possibilitar a celebração de um acordo de associação ainda em 2010. Com seus 27 Estados-membros, a UE possui quase $500 \mathrm{mi}$ lhões de habitantes, e um PIB de 14 trilhões de dólares, constituindo, assim, o principal espaço integrado do planeta. Um acordo de associação birregional movimentaria aproximadamente 750 milhões de 
pessoas, com um PIB estimado em 16,3 trilhões de dólares. Com estes dados a respeito, ambos os lados reiniciaram o diálogo, com vistas à instauração de condições objetivas que permitam a celebração do acordo.

\section{Considerações Finais}

As mudanças na política comercial comum da União Europeia ocasionadas pelo Tratado de Lisboa devem ser analisadas sob a dupla perspectiva de sua prática histórica e dos movimentos políticos e econômicos mais abrangentes que moldam a configuração institucional europeia de sua política comercial. Historicamente, as origens da União Europeia encontram-se na necessidade de superar as consequências desastrosas da Segunda Guerra Mundial e recompor a estrutura econômica e política dos Estados europeus em uma nova configuração, inédita, de organização internacional com características supranacionais. Com a consolidação do processo de globalização, a UE tornou-se há um tempo importante ator e vetor deste processo, como também serviu de exemplo a outras políticas de integração regional.

A globalização, por sua vez, é um fenômeno que possui múltiplas dimensões, e uma de suas características tem sido a crescente institucionalização das relações econômicas e comerciais internacionais. Neste sentido, uma das consequências negativas da crise iniciada em 2008, tem sido a fragilização do sistema multilateral, com a ampliação da dificuldade em concluir a Rodada Doha. Neste caso, os instrumentos jurídicos e institucionais que configuraram a globalização (apesar das suas falhas conhecidas) perdem gradativamente importância e práticas protecionistas ou desleais de comércio ganham nova dimensão, graças às condicionantes políticas nacionais. Em outros termos, taxas de desemprego elevadas nos países industrializados e poucas perspectivas de retomada da atividade econômica que venham melhorar as condições de emprego, sugerem uma nova agenda 
das relações comerciais internacionais, na qual o fortalecimento das instituições, ou seja, o aprofundamento da juridicidade, dificilmente será adotado em curto prazo. A circunstância de que a Europa não tenha sucumbido a uma espiral de protecionismo e políticas subvencionistas deve-se em grande medida, senão exclusivamente, à União Europeia e, em especial, ao fortalecimento e à expansão do mercado interno e da subsequente política comercial comum.

É neste contexto que os diversos acordos bilaterais ou regionais assumem uma importância redobrada, pois se sobrepõem ao sistema multilateral na organização dos fluxos internacionais de comércio e investimentos. Ou seja, o fracasso da Rodada Doha e a crise levaram a UE a intensificar a aproximação com a América Latina e o Caribe e acelerar as negociações com o Mercosul.

Por outro lado, sob a perspectiva da articulação de suas instâncias decisórias nacionais e supranacionais, o Tratado de Lisboa reconhece e institucionaliza a progressiva tendência de transferir definitivamente para as competências europeias a formulação e a condução da política comercial comum. A consolidação desta tendência decorre do processo de globalização e consequente liberalização comercial, em que são os temas conexos ao comércio internacional (em particular serviços, propriedade industrial e investimentos diretos externos) que necessitam consenso entre os Estados-membros e, na sua ausência, cabe aos órgãos da União impor interesses comuns e definir estratégias de negociação.

Neste sentido, houve a clara opção de inserir no âmbito das competências da União todos os setores afetos à política comercial comum. Mesmo nas poucas esferas do setor de serviços em audiovisuais e saúde, nas quais foi mantida a unanimidade de aprovação dos Estados-membros, não se retornou à prática dos acordos mistos, em que qualquer Estado poderia vetar a aprovação do acordo pela sua não ratificação nacional. Esta ampliação das competências europeias e a 
abolição dos acordos mistos diminuíram a influência que governos e Parlamentos nacionais podiam exercer sobre o conjunto da política externa europeia e não apenas sobre sua política comercial. Ou seja, mesmo que a importância do PE tenha sido aumentada, tornou-se, sob a perspectiva europeia, bem mais fácil negociar e celebrar um acordo comercial, já que não há mais necessidade de 28 ratificações. Por outro lado, a dilatação das atribuições do Parlamento Europeu no acompanhamento das negociações e da ratificação de uma série de acordos implica o questionamento de sua capacidade de apreciação crítica a respeito e, mais importante, o perigo de politização da PCC, ou, dependendo da perspectiva política utilizada, de maior participação e responsabilidade democrática.

No caso específico das negociações birregionais, duas observações são importantes. A primeira, de que, no caso do Mercosul, o aprofundamento da área de livre comércio, assim como a geração de uma base jurídica e institucional para o funcionamento da União Aduaneira, constitui um forte atrativo para tornar a região um foco central da estratégia comercial e de investimento dos agentes econômicos europeus e, principalmente, um dos requisitos europeus para a retomada das negociações. A segunda, de que a assimetria demográfica e de tamanho econômico entre os sócios do Mercosul pode, em grande medida, explicar a pouca disposição brasileira para aceitar as restrições dos demais parceiros (em especial da Argentina) na condução de sua política comercial externa. No entanto, é exatamente a necessidade de ampliar o acesso a mercados após o fracasso da rodada multilateral que impulsiona o Brasil a concordar com termos que há pouco considerava desvantajosos.

Já por parte da União Europeia, os obstáculos institucionais que dificultavam a negociação do complicado setor agrícola por parte de alguns (poucos) Estados-membros foram superados. No entanto, o desenlace das negociações está eminentemente ligado à percepção europeia da renovada importância econômica do acordo com o Merco- 
sul em um cenário de crise internacional persistente. Torna-se, portanto, necessário que a União Europeia defina internamente seus objetivos e estratégias comerciais e políticas em relação ao Mercosul e, neste contexto, oriente sua política comercial para a consecução de tais objetivos.

Segundo Peña (2010), surgiram novas condições que permitem o renovado otimismo a este respeito, em particular vontade política e visão estratégica que refletem interesses nacionais concretos, circunstâncias externas que geram a percepção de desafios políticos e econômicos, inclusive de ameaças, e um tecido de interesses cruzados nos setores econômico e social.

\section{Notas}

1. A supranacionalidade comunitária pode ser resumidamente descrita como sendo um sistema no qual os Estados-membros, voluntariamente, efetuam uma transferência de poderes de soberania em favor da então Comunidade Europeia. Por poderes de soberania, compreendem-se as atividades típicas do Estado, nos âmbitos executivo, legislativo e judiciário.

2. Para uma exposição extensa sobre as relações externas da UE e, em particular, sobre a política comercial comum, ver Kegel (2003, p. 15 ss.).

3. Até a entrada em vigor do Tratado de Lisboa, entendia-se como sendo o Tratado da Comunidade Europeia o conjunto do "direito comunitário primário", ou seja, os tratados constitutivos, os termos de adesão e os tratados que modificam ou complementam os tratados constitutivos, tais como interpretados pelo TJCE.

4. Parecer TJCE 1/94, de 15/11/1994, proferido a propósito da competência da CE para concluir o acordo que cria a Organização Mundial do Comércio. Neste caso, o final da Rodada Uruguai desencadeou uma verdadeira disputa de competências entre a Comissão e o Conselho (este, apoiado pelos Estados-membros). O foco de atrito estava em saber se a Comunidade possuiria competência exclusiva para celebrar o Acordo OMC e, especificamente, o Acordo Geral sobre o Comércio de Serviços (em inglês, General Agreement on Trade in Services [GATS]) e o Acordo sobre os Aspectos dos Direitos de Propri- 


\section{O Design Institucional da União Europeia e sua Repercussão nas Relações...}

edade Intelectual Relacionados ao Comércio (em inglês, Trade-Related Aspects of Intellectual Property Right [TRIPS]). A questão era particularmente problemática, pois a firme oposição dos Estados-membros à competência comunitária exclusiva nos acordos GATS e TRIPS poderia provocar a não celebração ou não ratificação do acordo OMC por um ou mais Estados-membros, colocando em risco a própria participação da Comunidade na OMC. Por outro lado, a Comissão sustentava que a CE poderia celebrar o acordo sozinha, e assim dispensar a participação autônoma dos Estados-membros no processo de vinculação internacional. Estabelecido o impasse, a Comissão recorreu ao TJCE, para que, através de um parecer, solucionasse o conflito. O Tribunal concluiu pela tese da competência não exclusiva da Comunidade no acordo TRIPS e em relação aos serviços que envolvem a deslocação transfonteiriça de pessoas.

5. Refere-se ao artigo 133 do Tratado da Comunidade Europeia, o qual continha disposições sobre a participação dos Estados na condução da política comercial comum da UE. O Tratado da Comunidade Europeia foi substituído pelo Tratado de Lisboa, de 2007.

6. A respeito deste virtual poder de veto por parte dos Estados-membros nos acordos mistos, dois exemplos são bastante ilustrativos: 1) A Quarta Convenção de Lomé entrou em vigor um ano e meio depois de sua celebração devido ao atraso nas ratificações nacionais, obrigando a Comunidade a adotar expedientes paliativos como medidas provisórias e a assinatura de acordos interinos. 2) No curso das negociações da Rodada Uruguai, a Comissão chegou a um pré-acordo (conhecido como compromisso de Blair House) com o governo dos Estados Unidos sobre a liberalização do comércio internacional de produtos agrícolas e a redução das subvenções internas, o qual deveria ter sido integrado no resultado final da rodada. O governo francês posicionou-se contrário a esse pré-acordo, ameaçando, inclusive, com o seu veto. Tal ameaça seria inútil se o compromisso de Blair House tivesse sido negociado e celebrado no âmbito de um acordo independente do restante da rodada. Nesta hipótese, a matéria em questão política e comércio agrícola - teria sido absolutamente coberta pela competência comunitária e aprovada pelo Conselho por meio de maioria qualificada. Porém, como os resultados da Rodada Uruguai formaram um só conjunto - single undertaking - no qual havia áreas de competência nacional, o governo francês pôde ameaçar com a não ratificação de todo esse conjunto, caso o compromisso agrícola - de competência exclusiva da Comunidade - não fosse modificado. Ver Kegel (2003, p. 46 ss.).

7. Este documento é conhecido pelas denominações "Tratado Constitucional" ou "Constituição Europeia", e não foi aprovado em respectivos referendos populares pela França e pela Holanda no ano de 2005. 
8. Art. 47 do TUE: "A União possui personalidade jurídica."

9. Torna-se claro, a partir dos dispositivos a este respeito no Tratado de Lisboa, que se procurou frear a expansão contínua das competências comunitárias em detrimento das nacionais. Em particular, procurou-se atenuar a utilização da “Teoria dos Poderes Implícitos", largamente adotada pelo TJCE no desenvolvimento da hermenêutica própria ao direito comunitário.

10. Segundo o art. $2^{\circ}$ do TFUE, quando os tratados atribuem à União competência exclusiva em determinado domínio, só a União pode legislar e adotar atos juridicamente vinculativos, e os próprios Estados-membros só podem fazê-lo se habilitados pela União. Porém, quando os tratados atribuam à União competência partilhada com os Estados-membros em determinado domínio, a União e os Estados-membros podem igualmente legislar nesse domínio. Importante observar que os Estados-membros exercem a sua competência na medida em que a União não tenha exercido a sua, e voltam a exercer a sua competência na medida em que a União tenha decidido deixar de exercer a sua. Já o art. $3^{\circ}$ dispõe que a União possui competência exclusiva, entre outros, em relação à União Aduaneira, à política comercial comum e à celebração de acordos internacionais quando previsto em ato legislativo da União, ou seja, necessário para que exerça sua competência interna.

11. Segundo o art. $6^{\circ}$ do TFUE, a União dispõe de competência para desenvolver ações destinadas a apoiar, coordenar ou completar a ação dos Estados-membros, em especial na proteção de saúde humana, indústria, cultura, turismo, educação, formação profissional, juventude e desporto, proteção civil e cooperação administrativa.

12. $\mathrm{O}$ art. $4^{\circ}$ do TFUE dispõe que a União possui competência compartilhada com os Estados-membros quando os tratados lhe atribuam competência em domínios não contemplados nos artigos $3^{\circ}$ e $6^{\circ}$. Em especial, as competências compartilhadas referem-se aos domínios relacionados a mercado interno, política social, coesão econômica, social e territorial, agricultura e pescas, ambiente, defesa do consumidor, transportes, redes transeuropeias, energia, espaço de liberdade, segurança e justiça, problemas comuns de segurança em matéria de saúde pública. No âmbito das ações relacionadas à pesquisa, à tecnologia e à ajuda humanitária, a atuação da União não impede a dos Estados-membros.

13. Segundo o art. 16 do TFUE, a União disporá também de competências exclusivas para a celebração de um acordo internacional quando tal celebração estiver prevista em um ato legislativo da União, quando for necessária para permitir que exerça sua competência interna ou na medida em que possa afetar normas comuns ou alterar o alcance das mesmas.

14. A aprovação formal e antecipada do Parlamento Europeu será necessária nos seguintes acordos: de Associação, de Adesão da União ao Convênio Europeu de Direitos Humanos, naqueles que criam um marco institucional específi- 


\section{O Design Institucional da União Europeia e sua Repercussão nas Relações...}

co, nos acordos que possuam consequências orçamentárias significativas e naqueles celebrados em setores nos quais se aplica o procedimento legislativo ordinário.

15. Este mecanismo de utilização da PCC para a conquista de objetivos não estritamente comerciais pode ser particularmente ilustrado com alguns exemplos. O primeiro, vinculado aos acordos que, desde a década de 1960, a então Comunidade Econômica Europeia vem celebrando com os chamados países ACP (Ásia, Caribe e Pacífico), em grande parte suas ex-colônias. Esses acordos de cooperação ao desenvolvimento também incluíram temas comerciais, permitindo, historicamente, que o desenvolvimento das ex-colônias servisse para que a Europa assumisse sua responsabilidade política, mas tendo igualmente propiciado a criação de vínculos que lhe garantiram acesso a matérias-primas baratas e influência política nessas regiões. Por outro lado, em virtude de considerações de ordem geopolitica, a UE continuamente priveligiou o Leste Europeu e a área do Mediterrâneo e do Norte da África em seus contatos políticos e comerciais. As experiências relacionadas ao desaparecimento do bloco soviético e a subsequente instabilidade política da região durante toda a década de 1990, bem como a contínua desagregação econômica do espaço do Mediterrâneo/Norte da África e as implicações relacionadas à imigração e à segurança levaram a UE a formular políticas diferenciadas para essas regiões. Em ambos os casos, a preocupação europeia esteve relacionada ao estabelecimento e à manutenção de um entorno geográfico estável, tanto política quanto economicamente. Em todos os casos, os instrumentos utilizados foram acordos que incluem vantagens comercias e instrumentos de cooperação.

16. Ver Comunicação da Comissão ao Parlamento Europeu e ao Conselho (2009), na qual são apresentadas estatísticas e relatório sobre o estado atual entre as duas regiões, também denominada "Comunicação sobre a América Latina".

17. O Sistema de Integração Centro-Americano (SICA) é formado por Belize, Costa Rica, El Salvador, Guatemala, Honduras, Nicarágua, Panamá e República Dominicana.

18. A Comunidade Andina de Nações é integrada por Bolívia, Colômbia, Equador e Peru.

19. Sobre a posição da Comissão em relação à política europeia para a região, ver a já citada Comunicação da Comissão ao Parlamento Europeu e ao Conselho (2009).

20. Ao menos é a percepção que alguns Estados-membros possuem a respeito. Ver Wissenschaftliche ([s.d.]). 


\section{Referências Bibliográficas}

BIELING, Hans-Jürgen; LERCH, Marika (Org.). Theorien der Europäische integration. Wiesbaden: VS Verlag für Sozialwissenschaften, 2006.

CARDOSO, Eliana; HOLLAND, Márcio. South America for the Chinese? A trade-based analysis. OECD Development Centre, Paris, Working Paper, n. 289, abr. 2010. Disponível em: <http://www.oecd.org>. Acesso em: ago. 2010.

COMUNICAÇÃO DA COMISSÃO AO PARLAMENTO EUROPEU E AO CONSELHO. A União Europeia e a América Latina: uma parceria entre protagonistas globais. COM (2009) 495/3. Bruxelas, 30 set. 2009. Disponível em: $<$ http://eeas.europa.eu/la/docs/com09_495_pt.pdf>. Acesso em: nov. 2010.

ESTEVE, Francina. El alcance de las competencias externas de la Unión Europea en el Tratado de Lisboa. In: PORTILLA, F. J. M. (Dir). Estudios sobre el Tratado de Lisboa. Granada: Editorial Comares, 2009.

EUROSTAT. External and intra-EU trade - a statistical yearbook. 1958-2008. Luxemburgo: Eurostat, European Comission, 2009.

GRATIUS, Suzanne. A Europa ainda representa algo na América Latina? In: III Cúpula América Latina, Caribe e União Europeia: considerações e recomendações. Rio de Janeiro: Konrad Adenauer Stiftung, 2006.

El ascenso post-crisis de América Latina. FRIDE - A European Think Tank for Global Action, 21 jan. 2010. Disponível em: <http://www.fride.org/publicacion/713/el-ascenso-post-crisis-de-america-latina>. Acesso em: mar. 2010.

GRIMMEL Andreas; JAKOBEIT, Cord. (Org.). Politische theorien der Europäischen integration. Wiesbaden: VS Verlag für Sozialwissenschaften, 2009.

KEGEL, Patricia Luiza. O marco jurídico-institucional da União Europeia e sua influência no contexto das negociações com o Mercosul. In: MARCONINI, M.; FLORES, R. (Org.). Acordo Mercosul-União Europeia. Além da agricultura. Rio de Janeiro: Konrad Adenauer Stiftung, 2003.

; AMAL, Mohamed. Mercosul e União Europeia: uma perspectiva estratégica. Revista de Estudos Europeus, Lisboa, v. 1, p. 91-128, 2007. 
O Design Institucional da União Europeia e sua Repercussão nas Relações...

NORTH, Douglass C. Instituciones, cambio institucional y desempeño económico. México: Fondo de Cultura Económica, 1993.

PEÑA, Felix. El despegue de las negociaciones Mercosur-UE: múltiples andariveles de un proceso con varios escenarios finales factibles. 2010. Disponível em: <http://www.felixpena.com.ar/index.php>. Acesso em: jan. 2010.

RIOS, Sandra Polônia; IGLESIAS, Roberto M. Anatomia do boom exportador e implicações para a agenda de negociações comerciais do Brasil. In: VEIGA, P. da M. (Coord.). Comércio e política comercial no Brasil: desempenho, interesses e estratégias. São Paulo: Singular, 2008.

WISSENSCHAFTLICHE Dienste Deutscher Bundestag [Serviço Cientifico do Parlamento Alemão]. Europa. Zehn Jahre Strategishe Partnerschaft EU-Lateinamerika und Karibik [Europa. Dez anos de parceria estratégica entre a EU e a América Latina e o Caribe], n. 13/09, [s.d.]. Disponível em: <http://www.bundestag.de/dokumente/wissenschaftlichedienste/index.html>. Acesso em: 10 mar. 2010.

WOOLCOCK, Stephen. The potential impact of the Lisbon Treaty on European Union external trade policy. European Policy Analysis, Swedish Institute for European Policy Studies, v. 8, 2008.

\section{Resumo}

\section{O Design Institucional da União Europeia e sua Repercussão nas Relações com a América Latina}

As negociações entre União Europeia e Mercosul com o objetivo de estabelecer uma relação estratégica birregional e um acordo comercial estão estagnadas desde 2004. Mesmo assim, o comércio vem aumentando substancialmente, e a UE consolidou-se como principal origem dos Investimentos Diretos Externos na região.

Em consequência da crise financeira e econômica, está ocorrendo um refluxo das instituições multilaterais, particularmente da Organização Mundial do Comércio, impulsionando, mesmo que por motivos distintos, a reabertura das negociações entre ambos os blocos. Neste quadro, a entrada em vigor 
do Tratado de Lisboa introduziu modificações no design institucional europeu, que alteraram o quadro normativo no qual as negociações ocorrem.

Palavras-chave: Instituições Europeias - Tratado de Lisboa - Política Comercial Comum - Mercosul

\section{Abstract}

\section{The Institutional Design of the European Union and its Effect on the Relationships with Latin America}

The negotiations between the EU and Mercosul with the objective to set up a strategic bi-regional partnership and a trade agreement are stagnant since the year 2004. Even with the interruption of the negotiation process, the trade flows between the two regions have been increasing substantially, and the EU has consolidated its position as the main source of Foreign Direct Investment in the Mercosul. On the other hand, one of the consequences of the global crisis is the retrocession of the role of Multilateral Institutions, particularly the case of the World Trade Organization, which stimulate the retaking of inter-regional block negotiations. In this relative new world configuration, the adoption of the Lisbon Treaty by all the EU-members introduces changes in the European institutional design of regional integration, which have affected the normative framework of international negotiations. The aim of the present paper is to address the effects of the Lisbon Treaty on the foreign trade policy of the EU, as well as the effects on the relationships between the EU and Latin America.

Keywords: European Institutions - Lisbon Treaty - Common Commercial Policy - Mercosul 